\title{
Long-Term Oncologic Result of Laparoscopic Versus Open Gastrectomy for Gastric Cancer: A Propensity Score-Matching Analysis
}

Si-yuan Wu ( $\nabla$ fiftyonedollars@mail.ndmctsgh.edu.tw )

Tri-Service General Hospital https://orcid.org/0000-0002-1636-8382

Meng-Hsing Ho

Tri-Service General Hospital

Hao-Ming Chang

Tri-Service General Hospital

Kuo-Feng Hsu

Tri-Service General Hospital

Jyh-Cherng Yu

Tri-Service General Hospital

De-Chuan Chan ( $\nabla$ chrischan1168@yahoo.com.tw)

Tri-Service General Hospital

\section{Research}

Keywords: Laparoscopic surgery, Gastric cancer, Postoperative complications, Survival, Recurrence

Posted Date: November 20th, 2020

DOI: https://doi.org/10.21203/rs.3.rs-111292/v1

License: (1) This work is licensed under a Creative Commons Attribution 4.0 International License.

Read Full License

Version of Record: A version of this preprint was published at World Journal of Surgical Oncology on April 7th, 2021. See the published version at https://doi.org/10.1186/s12957-021-02217-2. 


\section{Abstract}

Background: Laparoscopic gastrectomy is an acceptable procedure for early-stage gastric cancer; however, most patients are diagnosed at an advanced stage and older age in Taiwan. The feasibility and safety of applying laparoscopic gastrectomy in daily practice remains unclear. This study aimed to examine the short- and long-term outcomes of laparoscopic gastrectomy versus open procedures.

Methods: From 2007 to 2015, 192 patients who underwent open gastrectomy and 189 patients who underwent laparoscopic gastrectomy for gastric cancer at a single center were included. Propensity scorematching analysis was used to adjust selection biases associated with age, preoperative hemoglobulin, extent of resection, tumor size, and stage of disease. The demographics, perioperative parameters, postoperative short-term results, and 5-year survival data were analyzed.

Results: Open gastrectomy was more frequently performed in the elderly, larger tumor size, advanced stage of disease, and disease requiring total gastrectomy or combined organ resection. After propensity score-matching, 108 patients with laparoscopic gastrectomy were compared to 108 patients with open gastrectomy. The morbidity rates were not different in both groups (25.9\%), while hospital stay was shorter in the laparoscopic group (16.0 vs. 18.8 days, $p=0.04$ ). The 5 -year overall survival and diseasefree survival were superior in the laparoscopic group $(p=0.03$ and $p=0.01$, respectively); however, the survival differences were not significant in the subgroup analysis by stage. Laparoscopic gastrectomy had fewer recurrences than open gastrectomy. The pattern of recurrence was not different between the groups.

Conclusions: Laparoscopic gastrectomy can be safely applied in both early and locally advanced gastric cancer without compromising oncologic outcomes.

Trial registration: Retrospective registration.

\section{Background}

Gastric cancer (GC) is the fourth leading cause of cancer-mediated death worldwide and is more prevalent in Asian countries [1]. Surgery with radical gastrectomy and lymph node dissection is the single most effective treatment for localized, non-metastatic disease. In the last decade, several randomized controlled trials [2-6], including phase 3 trials [7-10] have indicated the feasibility of laparoscopic gastrectomy (LG) for treating early-stage GC. Compared to conventional open gastrectomy (OG), LG is associated with reduced blood loss, faster recovery, and a similar number of retried lymph nodes, but a longer operative time in these studies. Moreover, available data on long-term survival did not show statistical differences between laparoscopic and open surgery [11, 12]. In recent years, an increasing number of reports from specialized centers in Asian countries, including multi-center randomized trials $[13,14]$, have demonstrated that $L G$ is technically safe for locally advanced disease without compromising the quality of lymph node dissections. Long-term survival data from these large-scale studies are ongoing, although recent data have shown promising results [15-17]. 
In Taiwan, most GC patients are diagnosed at an advanced stage. Among patients who can be operated on, $68.1 \%$ had stage $>\mathrm{II}$, and $48.9 \%$ were of age $\geq 70$ years [18]. However, most studies regarding the safety of $L G$ often include younger patients with few comorbidities. The feasibility and safety of $L G$ in daily practice, which involves mostly treating elderly patients and advanced stage diseases, remains unclear.

At our institute, we expanded our indication and adopted laparoscopic surgery as the primary procedure for advanced GC as our experience developed. In recent years, either advanced age or the cancer stage did not necessarily preclude GC patients from LG. This practice had made our laparoscopic cohort closer to daily practice. However, a direct comparison between laparoscopic and open surgery would be unjustified if selection biases were not adjusted. In this study, we aimed to compare the outcomes between $L G$ and $O G$ for GC using propensity score-matching analysis.

\section{Methods}

We conducted a single-center, retrospective cohort study that included GC patients initially treated by radical gastrectomy at the Tri-Service General Hospital from January 2007 to December 2015. All patients were included except those with palliative procedures and open conversions. Clinical data were gathered from chart reviews after approval by the institutional review board of the Tri-Service General Hospital (TSGHIRB No. 1-106-05-098).

Patients were diagnosed with GC via endoscopic biopsy and went through subsequent staging work-up including contrast computed tomography to evaluate the extent of tumor involvement, as well as nodal status and to exclude distant metastasis. Endoscopic ultrasound was only performed to evaluate the feasibility of endoscopic mucosal resection or endoscopic submucosal dissection in clinically advanced GC. Gastrectomy with lymph node dissection was the standard treatment for locoregional disease. Patients eligible for surgery were assessed for comorbid conditions, nutritional state, and functional status. In patients with high perioperative risk, such as age over 80 years, American Society of Anesthesiologists (ASA) classification $\geq 3$, or Eastern Cooperative Oncology Group (ECOG) performance status $\geq 2$, the informed consent process involved anesthesiologists and cardiologists. Alternative palliative treatment options and associated prognostic data were also provided.

During the informed consent process before the operation, the surgeons informed the candidates regarding the pros and cons of $L G$ as well as the costs, after which the candidates decided between laparoscopic or open surgery. A diagnostic laparoscopy always preceded surgery to evaluate resectability. For localized resectable disease, the surgeon proceeded to perform open or LG based on the patient's decision. The absolute contraindications to laparoscopic surgery were: 1) tumors with direct invasion of the duodenum, pancreatic head, or esophagus; 2) bulky lymph nodes; and 3) unstable hemodynamics during surgery.

\subsection{Treatment}


All laparoscopic and open surgeries were performed by a single surgeon (DC Chan). The decision between distal or total gastrectomy was dependent on tumor location-a minimum of $5 \mathrm{~cm}$ of proximal safe margin was required. A D2 lymphadenectomy, according to Japanese guidelines [19], was the standard extent of lymph node dissection, while the extent could be D1 or D1 + in aged, comorbid patients, or in those with clinically early GC. In total gastrectomy for proximal GC, splenectomy was not routinely included in D2 lymphadenectomy, except if the tumor was adjacent to the splenic hilum or involved No. 10 or 11 lymph nodes. Combined organ resection was performed when the tumor grossly invaded the adjacent organs. The laparoscopic procedure started with the patient in the supine position with legs spread apart. Four trocar ports were created and arranged in a curved pattern: one 12-mm camera port at the umbilicus; one 5-mm and one 12-mm operator port at each side; and another 5-mm assistant port at the left subcostal region. Pressure for pneumoperitoneum was $12 \mathrm{mmHg}$. The dissection began at the greater curvature side, from the left to right gastroepiploic region, including total omentectomy and regional lymphadenectomy (No. 4sb, 4d, 6). The duodenum was transected by a linear stapler. Lymphadenectomy was then performed along the hepatoduodenal ligament (No. 12a), suprapancreatic region (No. 8a, 9, 11p), and lesser curvature side $(1,3,5,7)$. For distal gastrectomy, gastrojejunostomy was anastomosed using linear staplers in Roux-en-Y fashion after dividing the stomach. For total gastrectomy, esophagojejunostomy was anastomosed using a circular stapler in Roux-en-Y fashion after dividing the esophagus. Either procedure was anastomosed intracorporeally without additional incision. The specimen was retrieved from the extended umbilical incision with a wound protector. The sequences of the procedure were basically the same for both LG and OG.

Postoperative care was the same as for both approaches. Abdominal drains and Foley's catheter were routinely placed, but a nasogastric tube was usually not required. Patients aged over 80 years, with severe comorbidities, or who underwent lengthy procedures for extensive resection generally had postoperative intensive care. Patients were administered a liquid diet after first flatus. Hospital discharge required that patients could tolerate an adequate diet and had adequate control of medical diseases.

The patient surveillance and subsequent adjuvant chemotherapy after surgery were conducted by the same surgeon. Except for patients with early GC or contraindications, all patients underwent adjuvant chemotherapy. The regimen was generally capecitabine plus oxaliplatin, with or without paclitaxel. A follow-up was scheduled at least every three months in the first three years after completion of treatment. Laboratory studies, including tumor markers, were checked at each follow-up visit and abdominal ultrasound was performed every six months. Computed tomography (CT) scans were used to confirm recurrence if there was any clinical suspicion during surveillance.

\subsection{Outcomes evaluation}

The short-term outcome included operative time, hospital stay, and early complications. Early complications referred to adverse events within 30 days of surgery and were graded by extended ClavienDindo classification [20]. Complications confined to the abdomen were categorized into either 'local' or 'systemic.' The long-term outcomes were five-year overall survival and disease-free survival, which were calculated from the date of surgery. The last follow-up date was October 31, 2020. 


\subsection{Statistical analysis}

All analyses were performed using R 3.5.2 software (R Foundation for Statistical Computing, Vienna, Austria). Differences were considered significant at two-sided $p$ values $<0.05$. Descriptive statistics were expressed as mean \pm standard deviation for continuous variables and frequency (percentage) for categorical variables. Univariate analysis was performed using Mann-Whitney $\mathrm{U}$ test for continuous variables and Chi-square test or Fisher's exact test for categorical variables. Variables with $p<0.1$ were analyzed with the multiple logistic regression model to identify predictors of early complications.

Propensity score-matching was applied to minimize the imbalances associated with selection biases. In the model, propensity scores were developed, accounting for all factors significantly associated with either undergoing LG or OG. Accordingly, individual propensity scores were calculated through logistic regression modeling based on the following covariates: age; preoperative hemoglobulin; total gastrectomy; combined organ resection; tumor size; closest surgical margin; number of harvested lymph nodes; and stage. Patients undergoing LG and OG were then paired 1:1 on these propensity scores using nearest matching with caliper size $=0.1$. Balances between the groups were examined by graphical approaches, jitter plot and back-to-back histogram.

Following propensity score-matching, the short-term outcome between LG and OG was compared. The long-term survival between the two groups was estimated by Kaplan-Meier method and compared by logrank test.

\section{Results}

\subsection{Determinants that affect selection of procedures}

The year-wise changes in surgical practice and distribution of LG are shown in Fig. 1. After excluding 16 palliative surgeries and 12 conversions, a total of 381 consecutive patients were included. This included 192 patients with OG and 189 with LG (Table 1). The rate of advanced GC treated by laparoscopic approach increased by years, which had approached 90\% after 2014 . 
Table 1

Comparison of Perioperative Variables Between Cohorts Underwent OG or LG

\section{Before propensity score-matching After propensity score-matching}

\begin{tabular}{|c|c|c|c|c|c|c|}
\hline & $\begin{array}{l}O G(n= \\
192)\end{array}$ & $\begin{array}{l}\mathrm{LG}(\mathrm{n}= \\
189)\end{array}$ & $\begin{array}{l}\mathrm{p} \\
\text { value }\end{array}$ & $\begin{array}{l}O G(n= \\
108)\end{array}$ & $\begin{array}{l}\mathrm{LG}(\mathrm{n}= \\
108)\end{array}$ & $\begin{array}{l}\mathrm{p} \\
\text { value }\end{array}$ \\
\hline Age & $67.9 \pm 1.0$ & $64.6 \pm 1.1$ & 0.01 & $67.6 \pm 1.3$ & $67.8 \pm 1.5$ & 1.00 \\
\hline$\geqq 70$ & 97 (50.5\%) & $\begin{array}{l}76 \\
(40.2 \%)\end{array}$ & 0.04 & $53(49.1 \%)$ & $56(51.9 \%)$ & 0.68 \\
\hline Sex: male & $\begin{array}{l}135 \\
(70.3 \%)\end{array}$ & $\begin{array}{l}120 \\
(63.5 \%)\end{array}$ & 0.16 & $74(68.5 \%)$ & $69(63.9 \%)$ & 0.47 \\
\hline Body mass index & $24.2 \pm 0.3$ & $24.0 \pm 0.2$ & 0.48 & $24.4 \pm 0.3$ & $23.5 \pm 0.3$ & 0.03 \\
\hline Hemoglobin & $11.0 \pm 0.2$ & $12.4 \pm 0.1$ & $<0.01$ & $11.7 \pm 0.2$ & $11.8 \pm 0.2$ & 0.96 \\
\hline ASA Class & & & 0.66 & & & 0.30 \\
\hline 1 & $61(31.8 \%)$ & $\begin{array}{l}52 \\
(27.5 \%)\end{array}$ & & $36(33.3 \%)$ & $28(25.9 \%)$ & \\
\hline 2 & $97(50.5 \%)$ & $\begin{array}{l}101 \\
(53.4 \%)\end{array}$ & & $53(49.1 \%)$ & $53(49.1 \%)$ & \\
\hline 3 & $34(17.7 \%)$ & $\begin{array}{l}36 \\
(19.0 \%)\end{array}$ & & $19(17.6 \%)$ & $27(25.0 \%)$ & \\
\hline $\begin{array}{l}\text { Charlson comorbidity } \\
\text { index }\end{array}$ & $4.7 \pm 0.1$ & $4.6 \pm 0.1$ & 0.58 & $4.6 \pm 0.2$ & $4.9 \pm 0.2$ & 0.17 \\
\hline Prior abdominal surgery & $26(13.5 \%)$ & $\begin{array}{l}35 \\
(18.5 \%)\end{array}$ & 0.19 & $15(13.9 \%)$ & $18(16.7 \%)$ & 0.57 \\
\hline Extent of gastrectomy & & & $<0.01$ & & & 1.00 \\
\hline Distal gastrectomy & $\begin{array}{l}113 \\
(58.9 \%)\end{array}$ & $\begin{array}{l}142 \\
(75.1 \%)\end{array}$ & & 77 (71.3\%) & 77 (71.3\%) & \\
\hline Total gastrectomy & $79(41.1 \%)$ & $\begin{array}{l}47 \\
(24.9 \%)\end{array}$ & & $31(28.7 \%)$ & $31(28.7 \%)$ & \\
\hline $\begin{array}{l}\text { Extent of } \\
\text { lymphadenectomy }\end{array}$ & & & 0.25 & & & 0.58 \\
\hline Less than D2 & $37(19.3 \%)$ & $\begin{array}{l}28 \\
(14.8 \%)\end{array}$ & & $19(17.6 \%)$ & $16(14.8 \%)$ & \\
\hline D2 & $\begin{array}{l}155 \\
(80.7 \%)\end{array}$ & $\begin{array}{l}161 \\
(85.2 \%)\end{array}$ & & $89(82.4 \%)$ & $92(85.2 \%)$ & \\
\hline
\end{tabular}

Abbreviations. OG: Open gastrectomy, LG: Laparoscopic gastrectomy, ASA Class: American Society of Anesthesiologists Classification 


\begin{tabular}{|c|c|c|c|c|c|c|}
\hline \multirow[b]{2}{*}{$\begin{array}{l}\text { Combined organ } \\
\text { resection }\end{array}$} & \multicolumn{3}{|c|}{ Before propensity score-matching } & \multicolumn{3}{|c|}{ After propensity score-matching } \\
\hline & $41(21.4 \%)$ & $8(4.2 \%)$ & $<0.01$ & $10(9.3 \%)$ & $8(7.4 \%)$ & 0.62 \\
\hline Tumor size $(\mathrm{mm})$ & $52.1 \pm 2.0$ & $41.9 \pm 1.7$ & $<0.01$ & $49.1 \pm 2.8$ & $48.0 \pm 2.4$ & 0.85 \\
\hline Retrieved lymph nodes & $25.4 \pm 1.1$ & $30.2 \pm 1.1$ & $<0.01$ & $28.7 \pm 1.4$ & $28.4 \pm 1.4$ & 0.99 \\
\hline Metastatic lymph nodes & $5.1 \pm 0.5$ & $2.9 \pm 0.4$ & $<0.01$ & $3.6 \pm 0.5$ & $3.6 \pm 0.5$ & 0.96 \\
\hline Closest resection margin & $28.5 \pm 1.2$ & $34.4 \pm 1.1$ & $<0.01$ & $30.6 \pm 1.6$ & $30.5 \pm 1.4$ & 0.72 \\
\hline Pathologic T stage & & & $<0.01$ & & & 0.17 \\
\hline 1 & $28(14.6 \%)$ & $\begin{array}{l}69 \\
(36.5 \%)\end{array}$ & & $23(21.3 \%)$ & $29(26.9 \%)$ & \\
\hline 2 & $27(14.1 \%)$ & $\begin{array}{l}37 \\
(19.6 \%)\end{array}$ & & $22(20.4 \%)$ & $18(16.7 \%)$ & \\
\hline 3 & $44(22.9 \%)$ & $\begin{array}{l}43 \\
(22.8 \%)\end{array}$ & & $23(21.3 \%)$ & $33(30.6 \%)$ & \\
\hline 4 & $93(48.4 \%)$ & $\begin{array}{l}40 \\
(21.2 \%)\end{array}$ & & $40(37.0 \%)$ & $28(25.9 \%)$ & \\
\hline Pathologic N stage & & & $<0.01$ & & & 0.56 \\
\hline 0 & $66(34.4 \%)$ & $\begin{array}{l}108 \\
(57.1 \%)\end{array}$ & & $50(46.3 \%)$ & 49 (45.4\%) & \\
\hline 1 & $31(16.1 \%)$ & $\begin{array}{l}28 \\
(14.8 \%)\end{array}$ & & 15 (13.9\%) & 19 (17.6\%) & \\
\hline 2 & $40(20.8 \%)$ & $\begin{array}{l}23 \\
(12.2 \%)\end{array}$ & & $24(22.2 \%)$ & $17(15.7 \%)$ & \\
\hline 3 & $55(28.6 \%)$ & $\begin{array}{l}30 \\
(15.9 \%)\end{array}$ & & $19(17.6 \%)$ & BBG & \\
\hline Pathologic stage & & & $<0.01$ & & & 0.68 \\
\hline I & $40(20.8 \%)$ & $\begin{array}{l}94 \\
(49.7 \%)\end{array}$ & & 35 (32.4\%) & $41(38.0 \%)$ & \\
\hline II & $44(22.9 \%)$ & $\begin{array}{l}38 \\
(20.1 \%)\end{array}$ & & $25(23.1 \%)$ & $22(20.4 \%)$ & \\
\hline III & $\begin{array}{l}108 \\
(56.3 \%)\end{array}$ & $\begin{array}{l}57 \\
(30.2 \%)\end{array}$ & & 48 (44.4\%) & 45 (41.7\%) & \\
\hline $\begin{array}{l}\text { Lymphovascular } \\
\text { invasion }\end{array}$ & $\begin{array}{l}102 \\
(53.1 \%)\end{array}$ & $\begin{array}{l}66 \\
(34.9 \%)\end{array}$ & $<0.01$ & $51(47.2 \%)$ & $46(42.6 \%)$ & 0.49 \\
\hline
\end{tabular}




\begin{tabular}{|c|c|c|c|c|c|c|}
\hline \multirow[b]{2}{*}{ Extracapsular extension } & \multicolumn{3}{|c|}{ Before propensity score-matching } & \multicolumn{3}{|c|}{ After propensity score-matching } \\
\hline & $72(37.5 \%)$ & $\begin{array}{l}38 \\
(20.1 \%)\end{array}$ & $<0.01$ & $28(25.9 \%)$ & $28(25.9 \%)$ & 1.00 \\
\hline Poor differentiated & $\begin{array}{l}151 \\
(78.6 \%)\end{array}$ & $\begin{array}{l}134 \\
(70.9 \%)\end{array}$ & 0.08 & $77(71.3 \%)$ & $75(69.4 \%)$ & 0.77 \\
\hline Adjuvant chemotherapy & $74(38.5 \%)$ & $\begin{array}{l}64 \\
(33.9 \%)\end{array}$ & 0.34 & $36(33.3 \%)$ & $40(37.0 \%)$ & 0.57 \\
\hline
\end{tabular}

Patients who underwent LG were younger ( 64.6 vs. $67.9, p=0.01)$ and had a higher preoperative hemoglobulin (12.4 vs. $11.0 \mathrm{mg} / \mathrm{dL}, \mathrm{p}<0.01)$, but were not different from those who underwent open surgery in terms of preoperative comorbidities. Open surgeries were more frequently applied in larger tumor size (52.1 vs. $41.9 \mathrm{~mm}, \mathrm{p}<0.01)$, diseases that required total gastrectomy ( 41.1 vs. $24.9 \%, p<$ 0.01 ), and more locally advanced diseases (T4: 48.4 vs. $21.2 \%, p<0.01$; above N1: 49.4 vs. $28.1 \%, p<$ 0.01 ; stage 3: 56.3 vs. $30.2 \%, p<0.01$ ).

\subsection{Characteristics of propensity score-matched cohorts}

Patients were matched 1:1 based on determinants affecting selection of procedures as described above. The propensity score-matched cohort from the analysis included 216 patients: 108 in the OG group versus 108 in the LG group (Table 1). Covariates imbalance observed in the previous analysis were alleviated after matching, except for the lower body mass index (BMI) in the LG group (23.5 vs. 24.4, $p=$ 0.03). The matched cohorts were not statistically different in terms of age, sex, preoperative comorbidity status, extent of gastrectomy or lymph node dissection, stage, or rate of postoperative adjuvant chemotherapy.

\subsection{Comparison of short-term outcome in the propensity score-matched cohorts}

The short-term outcome is shown in Table 2. The LG group had a longer operative time (305.3 vs. 277.4 minutes, $p=0.03$ ), but shorter hospital stays ( 16.0 vs. 18.8 days, $p=0.041)$. Both groups had the same rate of early complication (25.9\%) with a similar rate of severe complications (Clavien-Dindo classification $\geq 3: 7.4 \%$ for $O G$ vs. $6.5 \%$ for $L G, p=0.79$ ). By individual event, $O G$ tended to have more dumping syndrome complication, while LG tended to have more pulmonary complications; however, none of the differences had statistical significance. 
Table 2

Comparison of short-term outcome in the propensity score-matched cohort

\begin{tabular}{|llll|}
\hline & OG $(\mathbf{n}=\mathbf{1 0 8})$ & LG (n=108) & p value \\
\hline Operative time & $277.4 \pm 6.8$ & $305.3 \pm 7.8$ & 0.03 \\
\hline Hospital Stay & $18.8 \pm 1.7$ & $16.0 \pm 0.9$ & 0.04 \\
\hline Overall complications & $28(25.9 \%)$ & $28(25.9 \%)$ & 1.00 \\
\hline Clavien Dindo class $\geq 3$ & $8(7.4 \%)$ & $7(6.5 \%)$ & 0.79 \\
\hline Local complications & & & \\
\hline Delayed gastric emptying & $3(2.8 \%)$ & $4(3.7 \%)$ & 1.00 \\
\hline Dumping syndrome & $5(4.6 \%)$ & 0 & 0.06 \\
\hline Ileus & $4(3.7 \%)$ & $4(3.7 \%)$ & 1.00 \\
\hline Chylous ascites & $1(0.9 \%)$ & $2(1.9 \%)$ & 1.00 \\
\hline Bleeding & 0 & 0 & \\
\hline Intraabdominal abscess & $6(5.6 \%)$ & $4(3.7 \%)$ & 0.75 \\
\hline Anastomotic leakage & $1(0.9 \%)$ & 0 & 1.00 \\
\hline Wound infection & $2(1.9 \%)$ & $2(1.9 \%)$ & 1.00 \\
\hline Systemic complications & & & 1.00 \\
\hline Pulmonary complications & $5(4.6 \%)$ & $11(10.2 \%)$ & 0.193 \\
\hline Cardiovascular events & u1 (0.9\%) & $2(1.9 \%)$ & 1.00 \\
\hline CRBSI & $3(2.8 \%)$ & $2(1.9 \%)$ & 1.00 \\
\hline Abbreviations. CRBSI, Catheter-related bloodstream infection & \\
\hline
\end{tabular}

\subsection{Comparison of the long-term outcome in the propensity score-matched cohorts}

The overall median follow-up time was $48.5 \pm 43.9$ months ( $54.2 \pm 34.2$ for $L G$ group vs. $60.0 \pm 51.7$ for OG group, $p=0.86$ ). The Kaplan-Meier survival curves for the propensity score-matched cohort are shown in Figs. 2 and 3. The LG group had significantly better survival than the OG group, either overall survival $(p=0.03)$ or disease-free survival $(p=0.01)$. In subgroup analysis by stages, $L G$ continued to have better overall survival (OS) and disease-free survival (DFS) than OG. However, none of these differences reached statistical significance across stages (stage 1: 5-year OS, 86.0 vs. $79.5 \%, p=0.40,5$-year DFS, 85.9 vs. $68.6 \%, p=0.21$; stage 2 : 5 -year OS, 86.4 vs. $70.6 \%, p=0.20,5$-year DFS, 81.6 vs. $63.2 \%, p=0.20$; stage 3 : 5 -year OS, 45.0 vs. $29.0 \%, p=0.10,5$-year DFS, 39.0 vs. $21.3 \%, p=0.07$ ). 
The patterns of the initial recurrences are shown in Table 3. More recurrence was observed in the OG group (42 vs 27), with locoregional being the most frequent pattern of recurrence. However, the distribution differences did not reach statistical significance.

Table 3

Comparison of recurrence pattern in the propensity score-matched cohort

\begin{tabular}{|llll|}
\hline & OG $(\mathbf{n = 1 0 8 )}$ & LG $(\mathbf{n = 1 0 8 )}$ & P value \\
\hline Initial recurrence & 42 & 27 & \\
\cline { 1 - 4 } Patterns & & & 0.33 \\
\cline { 1 - 3 } Locoregional & $16(38.1 \%)$ & $6(22.2 \%)$ & \\
\cline { 1 - 3 } Distant metastasis & $14(33.3 \%)$ & $13(48.1 \%)$ & \\
\cline { 1 - 3 } Peritoneal carcinomatosis & $12(28.6 \%)$ & $8(29.6 \%)$ & \\
\hline
\end{tabular}

\section{Discussion}

In the propensity-matched cohort, we found that $L G$ tended to have more favorable survival than $O G$ in treating GC, without compromising safety. The survival benefit was consistent for both early and advanced stages of diseases.

Several meta-analyses on non-randomized and randomized studies have compared the short-term outcome of LG versus OG for advanced GC [21-23]. Despite the longer operative time, patients undergoing LG tend to be benefit from less blood loss, faster recovery, and less morbidity. In the current study, we further showed the performance of LG in daily practice, in the context of treating mostly advanced stage disease and the elderly. In the propensity score-matched cohort, $62 \%$ of patients treated by laparoscopic approach were stage 2 or above, and $51.9 \%$ of patients were over 70 years of age (Table 1 ). The rate of advanced stage of disease and the elderly in the current study were very close to the registry data in Taiwan (68.1\% and $48.9 \%$, respectively) [18]. At this point, the rates of overall and specific morbidity for laparoscopic approach are not statistically different from the rates of open approach (Table 2). In addition, there was a trend of better survival in the LG group. Such findings may justify the routine application of LG in daily practice. The practice of applying LG for advanced GC on a large scale had been reported by studies from high-volume centers in Asia, which showed favorable short- and long-term results $[24,25]$. Equal or even superior oncologic outcome was possible when performed by experienced surgeons.

Oncologic integrity is the basic requirement for LG to be applied in GC; the efficacy of which is wellaccepted in early distal GC $[12,19]$. The recent multi-center randomized controlled trials from Korea (COACT 1001) and China (CLASS-01) investigating advanced GC have demonstrated comparable 3-year DFS for LG $[16,17]$. Noteworthy, in the COACT 1001 study, the noncompliance rate of D2 lymph node 
dissection was significantly lower in the laparoscopic arm for clinical stage III patients. Such a finding suggests that the efficacy of radical lymphadenectomy in LG could be more limited when applied to extensive lymph node metastasis, such as suprapancreatic stations. In our practice, the surgeon evaluated resectability from the beginning utilizing preoperative CT scans and diagnostic laparoscopy. The procedure would be converted to open if radical lymphadenectomy was technically difficult by laparoscopic approach, since conversion to open surgery is unlikely to result in inferior long-term outcomes [26, 27]. In the current study, the subgroup analysis for pathologic stage III disease showed that the 5 -year DFS was even better for the LG group (39.0 vs. $18.8 \%, p=0.06)$. In addition, the LG group had fewer overall recurrences than the OG group, with the dominant pattern of recurrence being distant metastasis rather than peritoneal carcinomatosis. Such results may help alleviate the concern of peritoneal seeding by pneumoperitoneum. Overall, LG was oncologically safe when resectability was properly evaluated.

The reduced surgical trauma by minimally invasive approach may not only result in faster postoperative recovery but better outcomes overall. One recent randomized controlled trial on patients who underwent neoadjuvant chemotherapy for advanced GC, showed that patients in the LG group were more likely to complete adjuvant chemotherapy and less likely to terminate because of adverse effects [28]. Though the 3-year survival data were pending, one could postulate a better chance of cure with completed courses of adjuvant chemotherapy. In our experience, the better survival in the LG group in the current study could also be attributed to better tolerance of adjuvant therapy. Patients who underwent LG tended to have faster recovery and better performance status postoperatively than those who underwent OG. The better oncologic outcome achieved by laparoscopic surgery had also been observed in colon cancer [29, 30]. The level of serum interleukin-6, which has been shown to be an independent prognostic biomarker for survival in colon cancer, was lower after laparoscopic surgery [31,32]. The reduced requirement of blood transfusion by laparoscopic approach may explain the better oncologic outcome as well [33].

Limitations of the current study come from its single-center, retrospective design. Residual biases associated with patient selection might not be fully considered by the propensity score-matching analysis. In addition, the regimen of adjuvant chemotherapy and the course of treatment were not standardized. However, the rate of advanced disease and frequency of elderly patients within this cohort was rather close to the true incidence in the general population. We believe this may provide surgeons with the outcome of $L G$ in real-world practice.

In conclusion, LG can be applied to most resectable GCs, and either an advanced stage of disease or old age should not be contraindications. Patients who undergo LG could not only benefit from faster postoperative recovery but also more favorable oncologic outcomes.

\section{Abbreviations}

ASA American Society of Anesthesiologists

BMI Body mass index 
CT Computed tomography

DFS Disease-free survival

ECOG Eastern Cooperative Oncology Group

GC Gastric cancer

LG Laparoscopic gastrectomy

OG Open gastrectomy

OS Overall survival

\section{Declarations}

Ethics approval and consent to participate: The study was approved by institutional review board of the Tri-Service General Hospital with waiver of informed consent (TSGHIRB No. 1-106-05-098).

Consent for publication: Not applicable

Availability of data and materials: The data that support the findings of this study are available on request from the corresponding author, DC Chan. The data are not publicly available due to restrictions in use of protected health information.

Competing interests: The authors declare that they have no competing interests

\section{Funding}

None

\section{Authors' contributions}

Chan DC contributed to the design of the work; Wu SY, Ho MH, Chang HM, and Hsu KF participated in the acquisition of data; Wu SY drafted the paper; and Chan DC and Yu JC revised the paper. All authors read and approved the final manuscript.

\section{Acknowledgments}

None

\section{Authors' information}

Si-Yuan Wu: fiftyonedollars@mail.ndmctsgh.edu.tw

Meng-Hsing Ho: hmh0208@mail.ndmctsgh.edu.tw 
Hao-Ming Chang: doc20364@gmail.com

Kuo-Feng Hsu: hsukf97@yahoo.com.tw

Jyh-Cherng Yu: doc20106@mail.ndmctsgh.edu.tw

De-Chuan Chan: chrischan1168@yahoo.com.tw

\section{References}

1. Crew KD, Neugut Al. Epidemiology of gastric cancer. World J Gastroenterol 2006; 12:354-62.

2. Hayashi H, Ochiai T, Shimada H, Gunji Y. Prospective randomized study of open versus laparoscopyassisted distal gastrectomy with extraperigastric lymph node dissection for early gastric cancer. Surg Endosc. 2005;19:1172-76.

3. Katai H, Sasako M, Sano T, Maruyama K. The outcome of surgical treatment for gastric carcinoma in the elderly. Jpn J Clin Oncol. 1998;28:112-5.

4. Huscher CG, Mingoli A, Sgarzini G, Sansonetti A, Di Paola M, Recher A, Ponzano C. Laparoscopic versus open subtotal gastrectomy for distal gastric cancer: five-year results of a randomized prospective trial. Ann Surg. 2005;241:232.

5. Lee JH, Han HS. A prospective randomized study comparing open vs laparoscopy-assisted distal gastrectomy in early gastric cancer: early results. Surg Endosc. 2005; 19:168-173.

6. Takiguchi S, Fujiwara Y, Yamasaki M, Miyata H, Nakajima K, Sekimoto M, Mori M, Doki Y. Laparoscopy-assisted distal gastrectomy versus open distal gastrectomy. A prospective randomized single-blind study. World J Surg. 2013;37:2379-86.

7. Kim HH, Hyung WJ, Cho GS, Kim MC, Han SU, Kim W, Ryu SW, Lee HJ, Song KY. Morbidity and mortality of laparoscopic gastrectomy versus open gastrectomy for gastric cancer: an interim report -a phase III multicenter, prospective, randomized Trial (KLASS Trial). Ann Surg. 2010;251:417-420.

8. Takagi M, Katai H, Mizusawa J, Nakamura K, Yoshikawa T, Terashima M, Ito S, Teshima S, Koeda K, Sano T, Fukushima N. A phase III study of laparoscopy-assisted versus open distal gastrectomy with nodal dissection for clinical stage IA/IB gastric cancer (JCOG0912): analysis of the safety and shortterm clinical outcomes. J Clin Oncol. 2015;33:4017.

9. Kim W, Kim HH, Han SU, Kim MC, Hyung WJ, Ryu SW, Cho GS, Kim CY, Yang HK, Park DJ, Song KY. Decreased morbidity of laparoscopic distal gastrectomy compared with open distal gastrectomy for stage I gastric cancer. Ann Surg 2016;263:28-35.

10. Katai H, Mizusawa J, Katayama H, Takagi M, Yoshikawa T, Fukagawa T, Terashima M, Misawa K, Teshima S, Koeda K, Nunobe S, Fukushima N, Yasuda T, Asao Y, Fujiwara Y, Sasako M. Short-term surgical outcomes from a phase III study of laparoscopy-assisted versus open distal gastrectomy with nodal dissection for clinical stage IA/IB gastric cancer: Japan Clinical Oncology Group Study JCOG0912. Gastric Cancer. 2017;20:699-708. 
11. Lee JH, Lee CM, Son SY, Ahn SH, Park DJ, Kim HH. Laparoscopic versus open gastrectomy for gastric cancer: long-term oncologic results. Surgery. 2014;155:154-164.

12. Kitano S, Shiraishi N, Uyama I, Sugihara K, Tanigawa N, Japanese Laparoscopic Surgery Study Group. A multicenter study on oncologic outcome of laparoscopic gastrectomy for early cancer in Japan. Ann Surg. 2007;245:68.

13. Hu Y, Huang C, Sun Y, Su X, Cao H, Hu J, Xue Y, Suo J, Tao K, He X, Wei H. Morbidity and mortality of laparoscopic versus open D2 distal gastrectomy for advanced gastric cancer: a randomized controlled trial. J Clin Oncol. 2016;34:1350-7.

14. Inaki N, Etoh T, Ohyama T, Uchiyama K, Katada N, Koeda K, Yoshida K, Takagane A, Kojima K, Sakuramoto S, Shiraishi N. A multi-institutional, prospective, phase II feasibility study of laparoscopy-assisted distal gastrectomy with D2 lymph node dissection for locally advanced gastric cancer (JLSSG0901). World J Surg. 2015;39:2734-41.

15. Kinoshita T, Uyama I, Terashima M, Noshiro H, Nagai E, Obama K, Tamamori Y, Nabae T, Honda M, Abe T, LOC-A Study Group. Long-term outcomes of laparoscopic versus open surgery for clinical stage II/III gastric cancer: a multicenter cohort study in Japan (LOC-A Study). Ann Surg 2019;269:887-94.

16. Yu J, Huang C, Sun Y, Su X, Cao H, Hu J, Wang K, Suo J, Tao K, He X, Wei H. Effect of laparoscopic vs open distal gastrectomy on 3-Year disease-free survival in patients with locally advanced gastric cancer: the CLASS-01 randomized clinical trial. JAMA. 2019;321:1983-92.

17. Park YK, Yoon HM, Kim YW, Park JY, Ryu KW, Lee YJ, Jeong O, Yoon KY, Lee JH, Lee SE, Yu W. Laparoscopy-assisted versus open D2 distal gastrectomy for advanced gastric cancer: results from a randomized phase II multicenter clinical trial (COACT 1001). Ann Surg. 2018;267:638-45.

18. Health promotion administration, Ministry of Health and Welfare: Cancer registry annual report, 2015, Taiwan. https://www.hpa.gov.tw/ (2017). Accessed 21 May 2018.

19. Japanese Gastric Cancer Association. Japanese gastric cancer treatment guidelines 2014 (ver. 4). Gastric Cancer. 2017;20:1-19.

20. Katayama H, Kurokawa Y, Nakamura K, Ito H, Kanemitsu Y, Masuda N, Tsubosa Y, Satoh T, Yokomizo A, Fukuda H, Sasako M. Extended Clavien-Dindo classification of surgical complications: Japan Clinical Oncology Group postoperative complications criteria. Surg Today. 2016;46:668-85.

21. Quan Y, Huang A, Ye M, Xu M, Zhuang B, Zhang P, Yu B, Min Z. Comparison of laparoscopic versus open gastrectomy for advanced gastric cancer: an updated meta-analysis. Gastric Cancer. 2016;19:939-950.

22. Zou ZH, Zhao LY, Mou TY, Hu YF, Yu J, Liu H, Chen H, Wu JM, An SL, Li GX. Laparoscopic vs open D2 gastrectomy for locally advanced gastric cancer: a meta-analysis. World J Gastroenterol. 2014;20:16750.

23. Wei Y, Yu D, Li Y, Fan C, Li G. Laparoscopic versus open gastrectomy for advanced gastric cancer: a meta-analysis based on high-quality retrospective studies and clinical randomized trials. Clin Res Hepatol Gastroenterol. 2018;42:577-90. 
24. Min SH, Won Y, Kim G, Lee Y, Park YS, Ahn SH, Park DJ, Kim HH. 15-year experience of laparoscopic gastrectomy in advanced gastric cancer: analysis on short-term and long-term oncologic outcome. Surg Endosc. 2020;34:4983-90.

25. Xu BB, Lu J, Zheng ZF, Huang CM, Zheng CH, Xie JW, Wang JB, Lin JX, Chen QY, Cao LL, Lin M. Comparison of short-term and long-term efficacy of laparoscopic and open gastrectomy in high-risk patients with gastric cancer: a propensity score-matching analysis. Surg Endosc. 2019;33:58-70.

26. Furnée EJ, Allaix ME, Morino M. Long-term oncologic outcome after laparoscopic converted or primary open resection for colorectal cancer: a systematic review of the literature. Surg Laparosc Endosc Percutan Tech. 2017;27:328-34.

27. Ye M, Jin K, Xu G, Lin F, Zhou Q, Tao K, Tao F. Short-and long-term outcomes after conversion of laparoscopic total gastrectomy for gastric cancer: a single-center study. J BUON. 2017;22:126-33.

28. Li Z, Shan F, Ying X, Zhang Y, E JY, Wang Y, Ren H, Su X, Ji J. Assessment of laparoscopic distal gastrectomy after neoadjuvant chemotherapy for locally advanced gastric cancer: a randomized clinical trial. JAMA Surg. 2019;154:1093-101.

29. Cianchi F, Trallori G, Mallardi B, Macrì G, Biagini MR, Lami G, Indennitate G, Bagnoli S, Bonanomi A, Messerini L, Badii B. Survival after laparoscopic and open surgery for colon cancer: a comparative, single-institution study. BMC Surg. 2015;15:33.

30. Law WL, Poon JT, Fan JK, Lo OS. Survival following laparoscopic versus open resection for colorectal cancer. Int J Colorectal Dis. 2012;27:1077-85.

31. Delgado S, Lacy AM, Filella X, Castells A, García-Valdecasas JC, Pique JM, Momblán D, Visa J. Acute phase response in laparoscopic and open colectomy in colon cancer: randomized study. Dis Colon Rectum. 2001;44:638-46.

32. Vainer N, Dehlendorff C, Johansen JS. Systematic literature review of IL-6 as a biomarker or treatment target in patients with gastric, bile duct, pancreatic and colorectal cancer. Oncotarget. 2018;9:29820-41.

33. Sun C, Wang Y, Yao HS, Hu ZQ. Allogeneic blood transfusion and the prognosis of gastric cancer patients: systematic review and meta-analysis. Int J Surg. 2015;13:102-10.

\section{Figures}




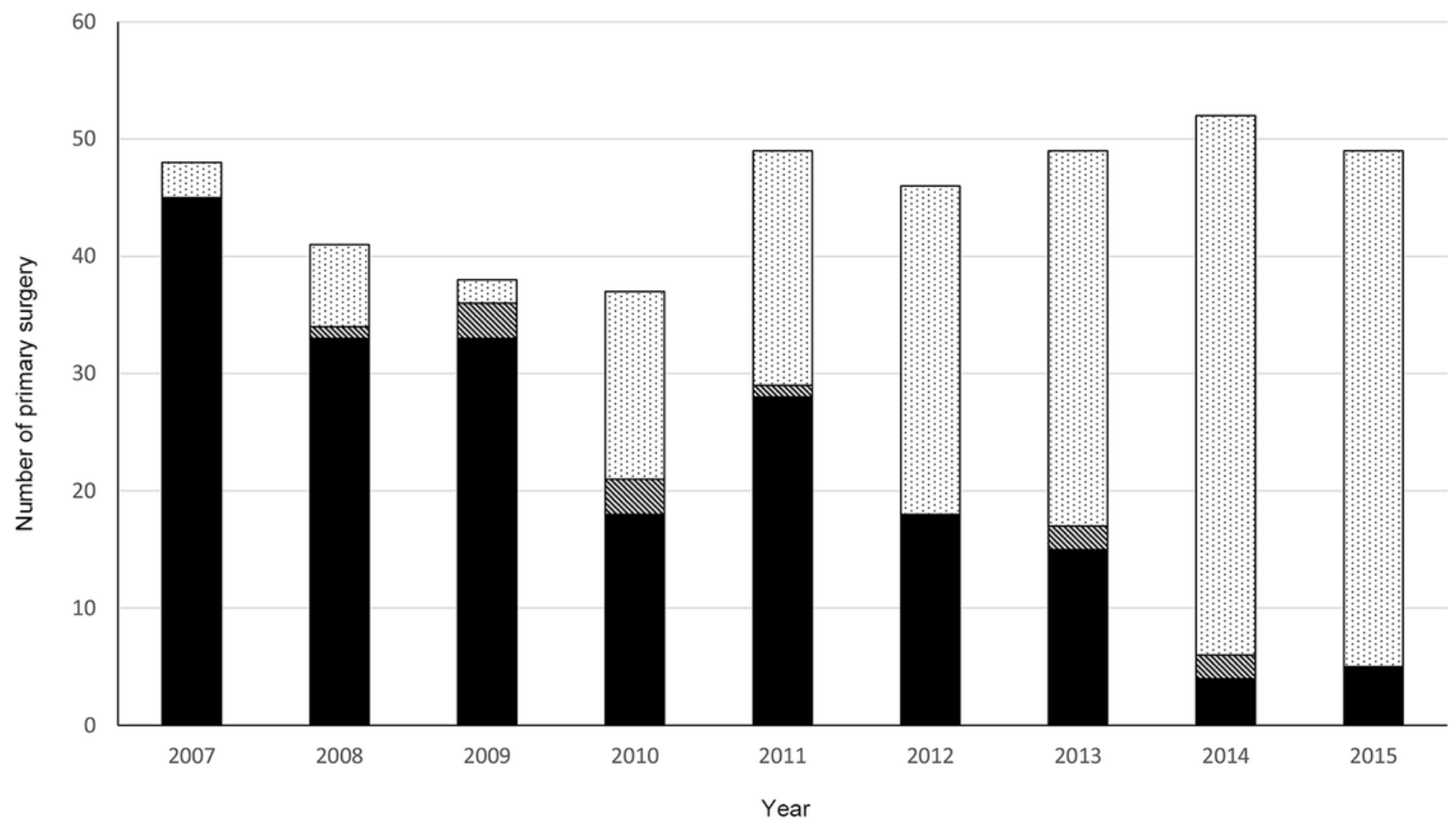

-OG $\mathbb{Q}$ Convert $⿴ 囗 \mathrm{LG}$

\section{Figure 1}

The year-wise change in surgical practice. Laparoscopic gastrectomy (LG) became the primary treatment for gastric cancer over years. OG: Open gastrectomy, LG: Laparoscopic gastrectomy
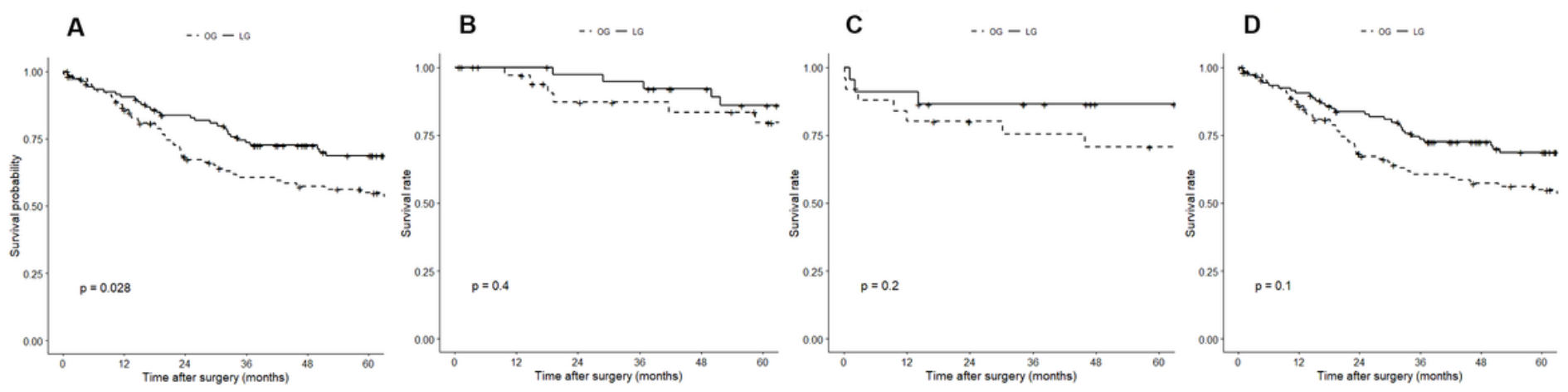

Figure 2

The 5-year overall survival after laparoscopic versus open gastrectomy estimated by the Kaplan-Meier method. a, all stages; b, pathologic stage 1 ; c, pathologic stage 2 ; d, pathologic stage 3 . 

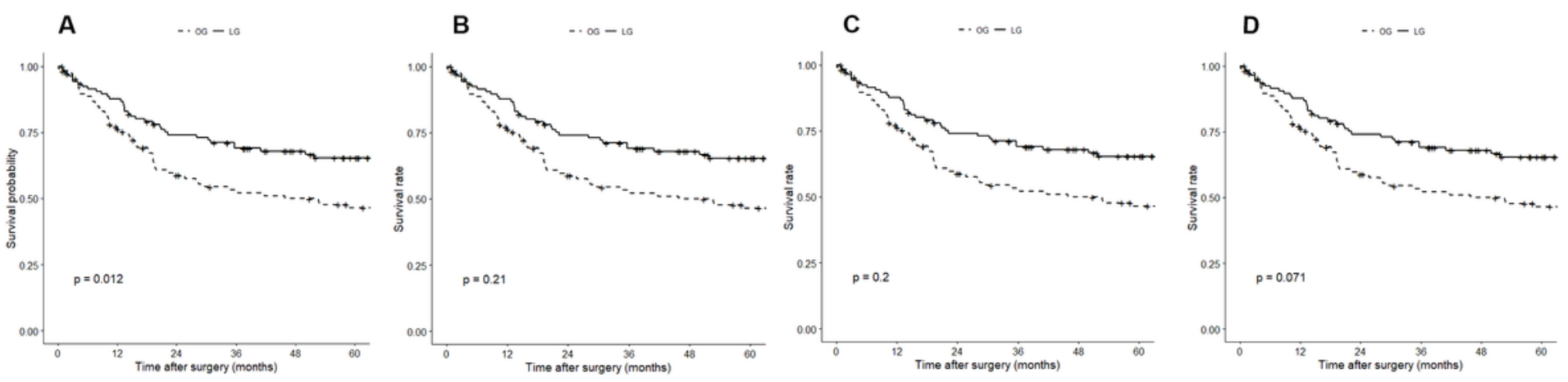

\section{Figure 3}

The 5-year disease-free survival after laparoscopic versus open gastrectomy estimated by the KaplanMeier method. a, all stages; b, pathologic stage $1 ; c$, pathologic stage $2 ; d$, pathologic stage 3 . 